\title{
POLÍTICAS PÚBLICAS DE EDUCAÇÃO NO ENSINO BÁSICO DO ESTADO DO PARANÁ: DA DÍVIDA SOCIAL À FORMAÇÃO PARA O MERCADO (1980-2000) ${ }^{1}$
}

\author{
Marisa Noda ${ }^{2}$ \\ Maria Terezinha Bellanda Galuch ${ }^{3}$
}

\begin{abstract}
Resumo
O presente artigo objetiva analisar de que forma diversos governos do Estado do Paraná, com plataformas políticas divergentes, elaboraram e implantaram políticas públicas para a educação do ensino básico fundamentados nas orientações de organismos internacionais como a Organização das Nações Unidas para a Educação, a Ciência e a Cultura (Unesco), o Banco Interamericano de Desenvolvimento (BID) e o Banco Internacional para Reconstrução e Desenvolvimento (BIRD). Mesmo que em seus discursos rechaçavam o modelo neoliberal sugerido por tais órgãos, tal fenômeno pode ser percebido entre as duas últimas décadas do século XX e o primeiro decênio do presente milênio. Além do estudo bibliográfico investigamos os planos de governos e os principais documentos norteadores da educação paranaense outorgados pela Secretaria de Estado da Educação (SEED) e Superintendência da Educação (SUED) paranaense. Tendo como sustentação teórica o materialismo histórico dialético concluímos que desde fins da década de 1980 a políticas educacionais levadas por distintos governantes se apropriaram do suporte econômico e ideológico sugeridos pelo neoliberalismo.
\end{abstract}

Palavras-chave: Educação. Políticas públicas. Neoliberalismo.

\section{POLÍTICAS PÚBLICAS DE EDUCACIÓN EN LA ENSEÑANZA BÁSICA DEL ESTADO DEL PARANÁ: DE LA DEUDA SOCIAL A LA FORMACIÓN PARA EL MERCADO (1980-2000)}

\section{Resumen}

El presente artículo objetiva analizar de qué forma diversos gobiernos del Estado de Paraná, con plataformas políticas divergentes, elaboraron e implantaron políticas públicas para la educación de la enseñanza básica fundamentadas en las orientaciones de organismos internacionales como la Organización de las Naciones Unidas para la Educación, la Ciencia y la Cultura (Unesco), el Banco Interamericano de Desarrollo (BID) y el Banco Internacional para la Reconstrucción y el Desarrollo (BIRD). Aunque en sus discursos rechazaban el modelo neoliberal sugerido por tales órganos, tal fenómeno puede ser percibido entre las dos últimas décadas del siglo XX y el primer decenio del presente milenio. Además del estudio bibliográfico investigamos los planes de gobiernos y los principales documentos orientadores de la educación paranaense otorgados por la Secretaría de Estado de Educación (SEED) y Superintendencia de la Educación (SUED) paranaense. Teniendo como sustentación teórica el materialismo histórico dialéctico concluimos que desde fines de la 
década de 1980 las políticas educativas llevadas por distintos gobernantes se apropiaron del apoyo económico e ideológico sugeridos por el neoliberalismo.

Palabras claves: Educación. Políticas públicas. Neoliberalismo.

\title{
EDUCATIONAL PUBLIC POLICIES IN BASIC EDUCATION OF THE STATE OF PARANÁ: FROM SOCIAL DEBT TO TRAINING FOR THE MARKET (1980-2000)
}

\begin{abstract}
The presente article aims to analyze how several State of Paraná governments, with divergent political plataforms, created and implanted public policy for the basic schooling education reasoned on the orientations from internacional organisms such as United Nations Educational, Scientific and Cultural Organization (UNESCO), the Inter-American Development Bank (IDB) and the International Bank for Reconstruction and Development (IBRD). Even if their speech rejected the neoliberal model suggested by such organs, this phenomenon can be perceived between the two last decades of XX century and the first decennial of the presente millennium. Besides the bibliographic study, we investigated the government plans and the main guiding documents from Paraná's education granted by the State Secretariat for Education (SEED) and the Paraná's Superintendency of Education (SUED). Taking as theoretical support the historical-dialectical materialism we concluded that since the late 1980s the educational politics guided by distinct rulers, have appropriated the ideological-economical support suggested by the neoliberalism.
\end{abstract}

Keywords: Education. Public policy. Neoliberalism.

\section{INTRODUÇÃO}

No estado do Paraná, desde o final da década de 1980, o currículo escolar foi alvo de políticas públicas que suscitavam discussões nas instituições de ensino básico, seja quando o estado, por meio da Secretaria de Estado da Educação (SEED), propôs a elaboração de currículos próprios, como ocorreu entre 1988 e 1990 com a elaboração do Currículo Básico para a Escola Pública do Estado do Paraná e entre 2003 e 2008, período em que foram gestadas as Diretrizes Curriculares da Educação Básica; ou na efetivação do currículo criado por instância federal, nos anos de 1996 e 1997, com a implantação dos Parâmetros Curriculares Nacionais nas escolas estaduais.

Essas ações distintas e separadas temporalmente, comumente, foram divulgadas como políticas públicas emanadas do Estado a fim de promover uma melhoria na educação, que, por consequência, eram anunciadas como benéficas para a sociedade, em especial para a parte economicamente desprivilegiada. Nesse caso, os documentos curriculares auxiliariam na formação dos jovens deste grupo social, dando-lhes a oportunidade de 
empregabilidade. O capitalismo, ao reforçar o caráter público, 'impessoal' e ‘autônomo' do Estado (WOOD, 2011), visa aproximá-lo dos que não são representados realmente por ele.

O Estado, impossibilitado de superar contradições que são constitutivas da sociedade - e dele próprio, portanto -, administra-as, suprimindo-as no plano formal, mantendo-as sob controle no plano real, como um poder que, procedendo da sociedade, coloca-se acima dela, estranhando-se cada vez mais em relação a ela. As políticas públicas emanadas do Estado anunciam-se nessa correlação de forças e, nesse confronto abrem-se as possibilidades para implementar sua face social, em um equilíbrio instável de compromissos, empenhos e responsabilidades. (SHIROMA; MORAES; EVANGELISTA, 2011, p. 8).

Nesta perspectiva, currículos oficiais, sejam eles elaborados ou implantados com caráter social, podem objetivar uma necessidade de mudanças sociais, mas quase sempre não correspondem às transformações almejadas pela sociedade, no entanto, podem ser utilizados para atenuar conflitos sociais qu

e a luta por transformações por vezes acarreta. (SHIROMA; MORAES; EVANGELISTA, 2011). Essa é uma característica bastante comum nas políticas públicas efetivas nos países periféricos nas décadas de 1980 e 1990, cujas reformas foram implantadas, muitas vezes, para responder a reivindicações populares, mas que atendiam apenas aos interesses neoliberais de formação. As mudanças curriculares ocorridas no estado do Paraná não foram isoladas; aconteceram em um contexto em que currículos foram modificados em resposta às políticas neoliberais.

\section{POLÍticAS EDUCACIONAIS NO ESTADO DO PARANÁ DE 1982 A 2002}

No estado do Paraná, o Partido do Movimento Democrático Brasileiro -PMDB-, venceu as eleições para governador, em 1982, com uma campanha de oposição aos militares, e o discurso que o pagamento da dívida social ${ }^{4}$, deixada pelos militares, deveria ser paga foi também utilizado pelo governador José Richa, que não cumpriu seu mandato na íntegra, retirando-se para concorrer a uma vaga para o senado em 1986. A política educacional desse governo anunciava que teria como modelo as bandeiras dos movimentos sociais de criar "escolas libertárias", auxiliando na formação de grupos sociais organizados, que forjariam seu destino. Para tal, conteúdos a serem ensinado nas escolas relevantes deveriam ser selecionados a fim de dotar as classes populares para os processos decisórios, administrativos, políticos, científicos ou tecnológicos. (CUNHA, 1991).

Em relação ao documento Políticas SEED/PR - fundamentos e explicação, que divulgava as diretrizes educacionais do governo José Richa, Mainardes (1995, p. 14) ressalta como um momento de participação e politização, denominado por Evangelista e Schmidt (1992, p. 280) de “[...] democracia patrocinada pelo Estado [...]” e por Cunha (1991, p. 236) de "Politização e populismo." Entre as ações destacadas nesse documento, estão: 
[...] questões como democratização do poder pela participação, descentralização da Secretaria de Estado da Educação, busca da qualidade de ensino, expansão da oferta educacional, garantia de acesso e permanência do aluno na escola, valorização do professor, resgate do compromisso político na ação e uma série de outras questões. (MAINARDES, 1995, p. 13).

De início, suas propostas de ação diferiam da política educacional do governo federal. No decorrer da gestão, observam-se incongruências que afastaram a educação paranaense de sua meta "libertária", defendida pela secretária de Estado da Educação do Paraná, Gilda Poli Rocha Loures', e explicitada no documento Políticas SEED/PR fundamentos e explicação. A proposta de educação libertária foi mesclada com falas das instituições religiosas de ensino, como as publicadas pela Revista da Associação de Educação Católica e transcritas para o Jornal da Educação, que orientavam as Semanas Pedagógicas. Nelas, os professores eram caracterizados como "[...] profetas dos novos tempos, baseando toda a sua caminhada educativa em uma metodologia humanizadora centrada na pessoa e não tanto nos conteúdos programáticos." (CUNHA, 1991, p. 241).

Por mais que criticassem a política econômica dos militares, marcada pelo subsídio de empréstimos estrangeiros, os governos de oposição que se elegeram eram herdeiros dessa política. Isso pode ser verificado pela continuidade do recebimento de créditos negociados com o Banco Internacional para Reconstrução e Desenvolvimento (BIRD) e o Banco Interamericano de Desenvolvimento (BID). Outro exemplo foi o prosseguimento do Projeto de Apoio ao Pequeno Produtor Rural (ProRural), financiado pelo BIRD. Com um viés para a educação, possibilitou a construção de 36 escolas com um custo entre US\$55,000 e US\$95,000 no estado do Paraná durante o governo de José Richa (1983 a 1986).

\footnotetext{
Ainda há de se considerar que uma das propostas da SEED, gestão 1983/1986, foi a democratização da educação via participação dos pais na escola. Essa proposta de 'administração escolar pela comunidade' nos parece um tanto pretensiosa e, sobretudo de cunho liberal. Visto que essa passagem da responsabilidade da administração escolar para a comunidade caracteriza-se como sendo omissão do estado diante de suas responsabilidades. Quer dizer, se a comunidade torna-se responsável e autônoma para gerenciar a escola, então o estado pode se ausentar, pois o compromisso que de fato é seu passou a ser assumido por outros sujeitos. (BACZINSKI, 2007, p. 29, grifo do autor).
}

Sobre esta proposição, a autora acima realiza a seguinte análise: as orientações pedagógicas do novo governo foram divulgadas pelo Jornal da Educação, tendo por objetivos guiar as Semanas Pedagógicas e representar uma via de comunicação dos órgãos governamentais com os professores. Evidencia-se que os textos divulgados priorizavam a valorização dos conteúdos que deveriam ser ensinados mediante métodos didáticos claros. Para o primeiro semestre de 1985, publicou-se o texto A escola da transição democrática, valorizando os conteúdos, recomendando livros como Escola e democracia, de Dermeval Saviani e apontando sua adesão aos princípios da pedagogia histórico-crítica. Nesse mesmo exemplar, o então diretor do Departamento do Primeiro Grau publicou artigo que apontava 
a escola como formadora do "espírito humanizado", possibilitando inferir, portanto, a não existência de coerência dentro de um mesmo órgão do governo ${ }^{7}$.

Mesmo com esse ecletismo pedagógico, é possível localizar, a partir de 1983, um afinamento da Secretaria de Educação paranaense com a pedagogia histórico-critica.

Segundo Baczinski, o documento:

\begin{abstract}
'Diretrizes de Governo: Política de Educação' de 1982 fundamentou-se na concepção educacional da Pedagogia Histórico-Crítica, refletindo sobre a sociedade como um todo articulado à educação. Pretendia-se retomar o ensino público gratuito, especialmente de $1^{\circ}$ Grau, garantindo a oferta mediante sua expansão. O principal objetivo da referida proposta era de proporcionar o acesso e a permanência dos alunos na escola pública e gratuita, principalmente aos alunos provenientes da classe trabalhadora, os quais estavam fora da escola, ou sendo eliminados dela. Levantava-se a bandeira de que a escola não deveria mais continuar contribuindo com a exclusão social de uma significativa parcela da sociedade, de quem já estava sendo negado o direito de participar das decisões políticas, sociais e econômicas por serem considerados ignorantes ou incompetentes. (BACZINSKI, 2007, p. 32, grifo do autor).
\end{abstract}

No documento, os conteúdos curriculares foram evidenciados como fundamentais para aproximar a "[...] escola da realidade social e política dos alunos" (CUNHA, 1991, p. 239), porém não houve uma orientação quanto à sistematização desses conteúdos e quais seriam privilegiados, ou seja, não se apresentou um projeto curricular. Frisou-se que os conteúdos deveriam encaminhar a criança ao conhecimento que transformaria sua vida e, consequentemente, a sociedade, sem haver encaminhamentos ou definição sobre quais conteúdos deveriam ser selecionados. "No plano pedagógico, a ação da SEED foi negativa com o desmonte das equipes de currículo e a inexistência de projetos curriculares na proposta política de governo." (PARRA, 2008, p. 73). A democratização passava mais pelo entendimento de que se deveria ofertar maior número de vagas nas instituições de ensino de Primeiro Grau, hoje ensino fundamental, do que priorizar a sistematização pedagógica do que seria trabalhado nas escolas.

Sendo assim, apesar da tentativa de unificação das práticas educacionais, durante o governo Richa, os professores permaneceram atuando de forma isolada, e até antagônica. Isso tudo em função da inexistência de projetos correspondentes com a proposta político-pedagógico da SEED, capaz de proporcionar fundamentação teórico-metodológica para a prática pedagógica das diversas disciplinas. (BACZINSKI, 2007, p. 37).

As mudanças sugeridas em busca de uma educação mais democrática não foram explicitadas sob a forma de projeto pedagógico, definido com apontamentos teóricos, metodológicos e de escolha de conteúdos. Os professores não receberam proposta norteadora da educação que o Estado defendia a não ser nos cursos de formação, que privilegiavam mais uma crítica ao modelo tecnicista, recomendado pelo governo militar, e menos o aprofundamento teórico da Pedagogia Histórico-Crítica. 


\title{
O PERÍODO DE 1987 A 1990
}

Em 1986, novo governo foi eleito no estado do Paraná, assumindo o mandato em 1987. Ao se referir à educação, três documentos nortearam suas propostas. Aqui vamos trabalhar com um deles, intitulado Projeto Pedagógico 1987-1990, fazia parte das propostas gerais do PMDB para o governo paranaense, cuja elaboração ocorreu mediante reuniões entre os partidários peemedebistas em diferentes regiões do estado. Martins (1997, p. 108) salienta que uma das características desse governo foi ser "[...] marcado pela reforma administrativa com caráter de racionalidade empresarial." Para "gerenciar" a educação, foi convidado o ex-secretário do Planejamento da gestão José Richa, Belmiro Valverde Jobim Castor, que aceitou o cargo de Secretário da Educação, tendo "administrado" a SEED até 1988. Outro ponto que baliza a construção do referido documento foi a menor participação dos simpatizantes peemedebistas do estado paranaense em sua elaboração.

\begin{abstract}
O documento Projeto Pedagógico 1987-1990 foi elaborado por menor número de representantes nos encontros regional-locais em função de que o PMDB, na condição de situação no Estado e, em nível nacional, não havia cumprido satisfatoriamente suas promessas de campanha e o Governo Sarney e a Nova república mostravam sinais de desgastes. (MARTINS, 1997, p. 108, grifo do autor).
\end{abstract}

O documento, apesar de se aproximar do projeto político-partidário do PMDB para a educação, trazia outra característica importante a ser discutida: uma faceta empresarial, "[...] em um país em que os recursos para a educação são tão escassos, a busca da racionalidade administrativa é um imperativo para evitar que os recursos - além de escassos - se percam na burocracia educacional." (PARANÁ, 1987a, p. v). Havia um consenso na gestão anterior de que a educação paranaense tinha a burocracia como empecilho. Naquele momento, o gestor da Secretaria da Educação afirmava que ela somente seria vencida com a racionalidade administrativa. Pode-se notar um discurso que foi posteriormente defendido pelo político Álvaro Dias: o Estado, de maneira geral, deveria ser gerido como uma empresa.

\section{ESCOLA COM AUTONOMIA: 1991 A 1994 - INSERÇÃO NEOLIBERAL}

"Nova era" era o slogan do governo de Roberto Requião, iniciado em 1991, para a educação paranaense. O programa do PMDB: Uma educação para a modernidade propostas de ações governamentais para o ensino do Paraná (PMDB, 1990), que, embora fosse um programa do partido, foi assinado por este governador, lançando a educação como setor prioritário de seu governo.

Mainardes evidencia que:

Embora quisesse romper ou ocultar, por razões políticas, suas ligações com outras gestões anteriores, vários itens do programa de Governo estão articulados, no mínimo, com a gestão 1987/1990, permeados por um ideário que tenta conjugar 


\section{Revista HIIST'TEIDBR On-line}

ISSN: 1676-2584

Artigo

doi: $10.20396 /$ rho.v18i2.8652356

modernidade, eficiência, gestão democrática e participação comunitária. (MAINARDES, 1995, p. 21).

Sobre a consolidação dessa proposta, houve o cumprimento das disposições administrativas e o não cumprimento das disposições pedagógicas. Como afirma Baczinski:

Dentre as ações propostas no programa de governo, várias delas não foram contempladas efetivamente, como exemplo, entre as ações pedagógicas e de magistério, 'a garantia de um piso salarial profissional para os professores em exercício', 'criação de mais dois níveis na carreira do magistério', 'implantação das escolas de $1^{\circ}$ grau em tempo integral', 'consolidação do Ciclo Básico de Alfabetização', 'maior investimento e atenção à Educação Especial envolvendo aspectos de prevenção', 'identificação e atendimento educacional', só pra citar alguns. No entanto, entre as ações administrativas, foi colocada em prática a redistribuição dos encargos educacionais previstos na Constituição Estadual entre Estado e Município, e não foi cumprida a proposta de aumento do número de salas de aula, a fim de universalizar a oferta do ensino fundamental, eliminando o turno intermediário. (BACZINSKI, 2007, p. 55).

Na Apresentação do projeto Construindo a Escola Cidadã no Paraná de 1992, é evidenciada a necessidade de democratização das instituições escolares.

[...] ampliando a autonomia administrativa e financeira das escolas bem como, buscando incentivar a participação da comunidade escolar no projeto pedagógico da escola e na escolha de seu diretor. Entendemos que a participação comunitária na gestão da escola, na definição dos seus rumos e na avaliação de seu desempenho é decisiva para o cumprimento de suas funções. (PARANÁ, 1992, p. 5).

Esse projeto, elaborado por Moacir Gadotti, reflete alguns pontos já anunciados no documento Uma educação para a modernidade - propostas de ações governamentais para o ensino do Paraná (PMDB, 1990), como a descentralização e a autonomia da escola. O documento marca o rompimento com as duas primeiras gestões peemedebistas e tem outra característica: o atrelamento às políticas neoliberais via ajustamento às orientações do Banco Mundial.

Segundo Noronha (2002), no início da década de 1970, medidas liberais e conservadoras eram defendidas pelo Banco Mundial. Em 1972, o presidente do Banco Mundial, Robert Strange McNamara, defendeu a urgência de se combater a pobreza, principalmente nos países periféricos. Para ele, as "necessidades básicas" deveriam ser asseguradas, o que estimulou os governos desses países a discursarem sobre priorização da nutrição, a moradia e a educação. Portanto, essa perspectiva de combate à pobreza, usando como via a educação, não era nova quando, em 1990, o Banco Mundial patrocinou a Conferência Mundial sobre Educação Para Todos, que apontou a necessidade de "[...] oferecimento de uma educação básica fundamental para promover o crescimento e o alívio da pobreza nos países em desenvolvimento." (NORONHA, 2002, p. 84). Essas políticas eram voltadas para promover uma educação que auxiliasse no alívio da pobreza, que seria combatida pela formação do indivíduo autônomo para lidar com a sua condição econômica, 
"[...] indivíduos mais efícientes na condução de sua própria pobreza, bem como controlar os conflitos sociais." (NORONHA, 2002, p. 86-87).

É possível perceber que essa perspectiva de autonomia, que é defendida pelo neoliberalismo, ganhou dimensão no decorrer na década de 1990, até ser prioritária com a política de descentralização, mas também é perceptível que estava presente em certos documentos norteadores da educação paranaense. Como chama a atenção Mainardes:

O referido Projeto, baseado na perspectiva da 'autonomia da escola', numa visão neoliberal, propunha que cada escola elaborasse o seu 'Projeto políticopedagógico', sem que a SEED estabelecesse diretrizes gerais para definir os 'projetos especiais' que a escola se propunha desenvolver e que seriam apoiados pela SEED. (MAINARDES, 1995, p. 24).

Características neoliberais também são apontadas por Figueiredo no documento:

O terceiro capítulo apresenta as 'perspectivas marcantes das escolas do Estado do Paraná', buscando afirmar que está nascendo uma nova filosofia, baseada na interação com a comunidade e com enfoque neo-humanista, voltada para uma educação comunitária, uma educação multicultural, uma educação ambiental e produtiva, isto é, preocupada com o mundo vivido e não apenas o mundo das idéias, uma 'educação interdisciplinar e transdisciplinar. Todo este movimento pedagógico da proposta educacional da gestão do governo Requião está voltado para trabalhar os valores como: 'saúde, lazer, alegria, convivência fraterna, busca de identidade (auto-conceito)' [...] pois a escola cidadã contribui para a construção de uma sociedade cidadã. (FIGUEIREDO, 2001, p. 120).

Em 1994, foi lançado pela SEED o documento Inovando nas escolas do Paraná, que, FIGUEIREDO (2001, p. 121), "[...] segundo representou o conteúdo proposto pelas escolas estaduais do Paraná, submetido às observações do professor Moacir Gadotti”, que assinou seu prefácio.

Divonzir Arthur Gusso, diretor geral do INEP, com o título - 'Mudar para construir: a inovação como estratégia de desenvolvimento' - enfatiza, entre outras questões '... o conceito de Educação Básica - a aquisição de competências cognitivas e sociais fundamentais cujo fulcro é a capacidade de aprender a aprender -, que justa e substancialmente, identifica a qualidade mais essencial dos sistemas educativos: proporcionar o aprender a ser'. (FIGUEIREDO, 2001, p. 122).

Duas outras afirmações de Figueiredo ajudam a entender o aparelhamento desse governo às recomendações dadas pelas agências internacionais para as reformas educativas e que julgavam necessárias nos países periféricos. A primeira é citada no prefácio do referido documento:

A iniciativa da Secretaria de Estado do Paraná, de abrir espaço à manifestação dos seus professores sobre o que fazem e acreditam ser necessário para melhorar seu ofício [...] põe em prática a proposição do Plano Decenal de Educação para Todos e de situar a escola como 'lugar privilegiado e autônomo de gestação e desenvolvimento da aprendizagem e da formação do cidadão, incentivando-lhe a criatividade, a capacidade de inovação e de ajustamento cultural ao seu entorno social. (FIGUEIREDO, 2001, p. 122). 
A segunda aparece na sua Apresentação, assinada pelo superintendente de educação da SEED, Antônio João Mânfio:

\begin{abstract}
A Secretaria de Estado da Educação, após 30 meses de vigência das Diretrizes da Política Educacional do Governo Roberto Requião, denominada Educação para a Modernidade, apresenta Inovando nas Escolas do Paraná. Trata-se de um documento construído por dezenas de mãos sobre uma realidade edificada por milhares de outras mãos e de cabeças, naturalmente. [...] trata-se mais de um álbum de retratos falados de iniciativas pontuadas que se multiplicam como cogumelos nos campos após fecundados pelas chuvas benignas da primavera. Essa primavera na educação do Paraná nasce da convergência de inúmeros esforços feitos pelo governo, magistério, comunidade e opinião pública. (PARANÁ, 1994, p. 13).
\end{abstract}

Segundo Gonçalves et al. (2003, p. 88), o governo Requião realizou empréstimo diretamente junto ao BIRD para financiar a educação paranaense, "[...] por primeiro, um financiamento para um projeto relativo ao $1^{\circ}$ grau, [...] para, posteriormente, dirigir-se ao BID solicitando recursos que permitissem o desenvolvimento do Projeto de Ensino Médio."

Parra (2008) também evidencia a busca de créditos realizados pela SEED junto às agências internacionais para implantar o Projeto de Qualidade no Ensino Público, que teve início no governo de Jaime Lerner, em 1994.

\begin{abstract}
Embora efetivado no governo Lerner, esse projeto surge durante a gestão Requião, quando da negociação do Estado do Paraná com o BID - Banco Interamericano de Desenvolvimento em relação a empréstimos para o setor educacional, considerado por esse órgão financiador como instrumento de desenvolvimento social e de avanço tecnológico. A conseqüência é o atrelamento, por meio de financiamentos e empréstimos, da política econômica nacional e paranaense, aos interesses do capitalismo internacional, ampliando o processo de acumulação capitalista. (PARRA, 2008, p. 64).
\end{abstract}

Fazem parte ainda do acervo normalizador da educação dessa gestão os seguintes documentos: Avaliação Escolar: Um Compromisso Ético (PARANÁ, 1993), cuja consultoria foi de Eronita Barcelos, na época docente da Universidade de Unijuí, também consultora do Construindo a Escola Cidadã no Paraná (PARANÁ, 1992) e A proposta pedagógica como instrumento de qualidade e de gestão da escola: conteúdo, processo de elaboração, acompanhamento e avaliação: a participação do magistério (MÂNFIO, 1993), cuja responsabilidade foi de Antonio João Mânfio, que ocupava o cargo de Superintendente de Educação do estado do Paraná.

\title{
PERÍODO DE DESCENTRALIZAÇÃO: 1983 A 1994 - ARTICULAÇÕES NEOLIBERAIS
}

O ano de 1994 marcou o fim de quatro mandatos de governadores eleitos pelo PMDB no estado do Paraná. Em todas as gestões, o partido criou documentos para direcionar ou, pelo menos, informar sobre sua política de governo. A educação teve espaço nesses norteamentos, indicada como campo privilegiado de atuação desses governadores, aquela 
que receberia “[...] uma atenção maior do Estado.” (PARANÁ, 1984, p. 01). Como se vê, além dos planos de governos advindos do partido político, a SEED orientou a rede de ensino por meio de projetos, documentos e programas que traziam recomendações administrativas e pedagógicas às quais as escolas deveriam seguir.

Quanto às orientações na administração, nesses 12 anos de governo, a descentralização administrativa foi consolidada. Iniciada no governo José Richa (19831986), primeiro impôs-se como descentralização da SEED, com a criação dos Núcleos Regionais de Educação, a municipalização dos anos iniciais do ensino fundamental e eleições para diretores escolares.

\begin{abstract}
O processo de Municipalização do Ensino Fundamental do Estado do Paraná inicia-se em 1983 com a criação de convênios com as prefeituras municipais para a contratação de pessoal técnico-administrativo, serviços gerais e professores. O Estado financiava um salário mínimo para cada contratado. A contrapartida do município eram as obrigações contratuais e a administração dos recursos e do pessoal. Esta modalidade de convênio ocorre até meados de 1991. A sua regularização era feita através de renovações que se efetivavam anualmente. (LIMA; VIRIATO, 2005, p. 6).
\end{abstract}

Quanto às eleições de diretores, não ocorreram de forma direta: pais, alunos, professores e funcionários elegiam três candidatos entre os quais o governador nomeava um para dirigir a escola, sem critérios estabelecidos. Tal modelo de escolha não agradou aos professores, nem a sua entidade representativa: a Associação dos Professores do Paraná (APP).

O governo Álvaro Dias (1987-1991) deu continuidade ao processo de descentralização da SEED, mediante a ampliação de oito para 22 Núcleos Regionais de Educação (BACZINSKI, 2007, p. 42), a Municipalização e a proposta de um modelo próprio de descentralização. No documento Projeto Pedagógico 1987-1990, é possível perceber que, pela chamada função e participação da comunidade escolar, o governo pretendeu delegar responsabilidades para os cidadãos, processo de que evidencia a desobrigação do Estado pela educação pública, fortalecendo a tese liberal: “[...] o menos de Estado e de política possível.” (FIORI, 1998, p. 212). Lima e Viriato (2005) citam a contribuição de Lupatini para se entender que esse procedimento se caracterizou

[...] muito mais como transferência de responsabilidade pela gestão e manutenção das escolas, obedecida às normas e diretrizes governamentais, do que como deslocamento do eixo de poder, permitindo que as políticas e as decisões sejam formuladas via participação. (LUPATINI, apud LIMA; VIRIATO, 2005, p. 7).

A autonomia da escola, que, de acordo com o Projeto Pedagógico, representava democratização, propunha "[...] dar às escolas a maior autonomia possível em relação à gestão do seu cotidiano, concentrando recursos na própria escola para que a administração do dia-a-dia seja desburocratizada e simplificada" (PARANÁ, 1987a, p. vi) e ainda "[...] o que se espera, na atual conjuntura, é o apoio da comunidade no sentido de unir esforços, 
multiplicar e inovar formas de atuação, raciocinar a utilização de recurso público." (PARANÁ, 1987a, p. 16). Ao propor a autonomia das escolas e a participação da comunidade, o governo retira de sua responsabilidade de direção, “[...] enquanto ao Estado caberia manter centralizadas as funções de fixar padrões, facilitar os insumos que influenciam o rendimento escolar, adotar estratégias flexíveis [...]”. (SILVA; AZZI; BOCK, 2007, p. 14), implantando políticas neoliberais, conforme apregoa o Banco Mundial. Destacam:

O Documento trata ainda do conceito de Autonomia da Escola 'conferindo-lhe maior autonomia, na medida em que o esforço conjunto é capaz de superar situações outrora extremamente dependentes de soluções advindas do poder público'. É uma situação confortável para o Estado, pois responsabilizando a escola ao instituir a participação instrumental e a autonomia tutelada, conduz à aceitação da própria escola em assumir responsabilidades, sendo que os órgãos centrais continuam por determinar as políticas de controle. (LIMA; VIRIATO, 2005, p. 7-8, grifo do autor).

Também chama atenção no Projeto Pedagógico do período de 1987-1991 o fato de o novo organograma da SEED falar em eficiência e racionalidade administrativa. Segundo Martins:

Embora tal perspectiva pareça semelhante à do regime militar, o documento reitera a crítica à ditadura, ao tecnicismo, aponta para uma nova concepção de educação: A Escola Pública como espaço onde a classe trabalhadora deve se apropriar dos conhecimentos validados universalmente, mas apropriados pela classe que detém os meios de produção. (MARTINS, 1997, p. 109).

No governo de Álvaro Dias, a perda salarial do magistério foi grande. Segundo Mainardes (1995, p. 20), a partir de setembro de 1987, o salário dos professores foi sofrendo um decréscimo: professores com carga horária de 20 horas semanais com licenciatura plena recebiam de 6,3 salários mínimos em março de 1987 e, em maio de 1989, havia reduzido em torno de 3,9 salários mínimos.

No governo Roberto Requião, 1991-1994, houve o fortalecimento da descentralização e a busca da desvinculação com os governos anteriores, embora pertencesse ao mesmo partido político. O governador conseguiu cumprir parte das metas administrativas anunciadas em seu programa de governo, consolidou a municipalização do ensino dos anos iniciais do ensino fundamental, apresentou o Regimento Escolar Único para as escolas paranaenses, forçando que as unidades escolares formalizassem seus regimentos e convocou as escolas a criarem seus Conselhos Escolares, nos quais a comunidade deveria estar representada, cumprindo uma orientação dos organismos internacionais: possibilitar a participação da sociedade nas decisões da escola.

Sua gestão foi marcada por uma participação mais incisiva sobre a SEED e seus titulares, cuja autonomia era limitada, havendo uma centralização intensa do governador sobre as políticas dessa Secretaria de Estado, o que Mainardes (1995, p. 25) denominou “"...] política educacional autoritária”, procedimento que reforça o conservadorismo neoliberal. À 
escola, pode-se conceder uma participação, mas, na Secretaria que coordena a rede de ensino, que toma as decisões, ficava sobre mando direto do governador.

Assim, tanto a municipalização quanto a política de orientação do Regimento Escolar Único não foram discutidos pelas partes interessadas. O magistério tampouco foi consultado, mostrando mais uma vez que a participação oferecida à comunidade não se estendia aos professores. Esse posicionamento do governador levou a um descontentamento da Associação do Professores do Paraná (APP) ${ }^{8}$, que foi se agravando com o passar da gestão, sobretudo devido à transformação da eleição de direção para consulta à comunidade e a obrigatoriedade de o diretor escolhido pela comunidade ter que passar por processo de capacitação administrativo-pedagógica preparada pela SEED.

Uma ação do governo, considerada de cunho administrativo, foi o Plano Estadual de Capacitação Docente, que não demonstrou articulação com as próprias políticas daquele governo.

[...] em 1992, a SEED elaborou o referido plano, no qual cada professor deveria participar, no mínimo, de 80 horas de cursos de capacitação. Para isto, buscou integrar os 3 graus de ensino, cabendo às Instituições de Ensino Superior do estado desenvolverem ações articuladas com os Núcleos Regionais de educação para a capacitação docente. Porém os cursos de capacitação não estavam articulados a um projeto educacional mais amplo e, na maioria dos casos, tais cursos não priorizavam questões relevantes e necessárias, tais como a discussão do Currículo Básico. (MAINARDES, 1995, p. 24).

Se as políticas administrativas dos governantes demonstram, na maioria das vezes, insensibilidade frente às necessidades do magistério paranaense, com as ações pedagógicas, não foi diferente. Os anos de governo peemedebista foram marcados pela descontinuidade, gerando instabilidade nas unidades de ensino. Mainardes (1995) aponta mais políticas descontínuas, antagônicas em relação ao processo pedagógico, especialmente nos dois últimos governos.

No período de 1982 a 1985, verifica-se que pouco se caminhou em relação às questões pedagógicas. Martins (1997) destaca o abandono pedagógico das escolas paranaenses nesse período, o que motivou uma carta dos docentes que prestavam serviços à SEED, em junho de 1985, intitulada Posicionamento dos educadores a serviço da SEED. Mesmo sem uma sistematização pedagógica, nas orientações advindas da Secretaria naquele momento, verifica-se o que Baczinski analisa como prenúncio da Pedagogia HistóricoCrítica:

No entanto, as ações educacionais do governo em questão relatadas até o momento nos indicam que o prenúncio da apropriação da Pedagogia Histórico-Crítica como fundamento teórico balizador das políticas educacionais, tendo como objetivo a redemocratização escolar constituiu-se num discurso ideológico visando ao convencimento/crença em reais transformações no âmbito educacional. A concepção teórica da Pedagogia Histórico-Crítica foi utilizada como discurso falado e escrito, que simboliza a transição de uma sociedade autoritária para uma sociedade democrática, nas palavras de $\operatorname{NOGUEIRA~(1993,~p.~63):~'são~formas~}$ 
simbólicas de ir tecendo a transição, já caracterizada pelos partidos da ordem como lenta, gradual e segura'. (BACZINSKI, 2007, p. 43, grifo do autor).

No documento Políticas SEED-PR: fundamentos e explicitações (1984), não há uma discussão de currículo. Fala-se da importância dos conteúdos e métodos a serem dominados pela população: “[...] a soma de conhecimento já acumulados, através dos tempos, para que todos possam se incumbir de criar uma nova sociedade" (PARANÁ, 1984, p. 5) e que a escolha de conteúdos "[...] relevantes (para os indivíduos e a sociedade) não se desvincula da escolha do método de análise dos problemas que o professor adota." (PARANÁ, 1984, p. 7). Segundo Mainardes (1995, p. 15), naquele momento, predominava a "[...] inexistência de projetos curriculares para as áreas ou disciplinas unificadas pela proposta política da SEED".

Na segunda gestão do governador Álvaro Dias (1987/1990), o encaminhamento pedagógico pode ser sentido com uma direção mais coesa: o documento de anúncio da proposta de governo, Diretrizes de governo para debate, comunicava a renovação pedagógica como meta, e que, no caso, não seria uma renovação se se considerar a ineficiência do governo anterior com relação às ações didáticas. A grande ação pedagógica que norteou outras políticas educacionais desse governo foi a implantação do Ciclo Básico de Alfabetização ${ }^{9}$ como prioridade das políticas da SEED, que trouxe a necessidade de uma definição de currículo, anunciada no documento: Projeto Pedagógico 1987-1990. Conforme segue:

\begin{abstract}
Não se deve confundir currículo com o total das atividades desenvolvidas sob a responsabilidade da escola, nem reduzi-lo apenas ao seu conteúdo. A dimensão nova reside também na consideração da prática social do aluno como referência para a organização desses conteúdos e de toda a relação pedagógica. [...] No currículo, há uma essencialidade que, se não for cumprida, descaracteriza a escola e compromete sua função precípua. É preciso adequá-la às características dos alunos que atualmente frequentam a escola pública. (PARANÁ, 1987a, p. 4).
\end{abstract}

Tal posicionamento fornece uma visão de como o currículo seria entendido por esse governo, "[...] dentro de um quadro mais geral de referência teórica, histórica e política": como uma "[...] política educacional que garanta a socialização do conhecimento como um dos requisitos para se conseguir maior justiça social e econômica.” (PARANÁ, 1987a, p. 5). Com esta visão, a Proposta Pedagógica 1987-1990 toma o referencial teórico da Pedagogia Histórico-Crítica, e a aproximação fica mais evidente no significado que o referido documento dá à escola:

Numa sociedade democrática, a escola é um instrumento valioso, na medida em que possibilita o acesso ao conhecimento elaborado, proporcionando uma mediação entre o "saber" e o "fazer". Essa mediação é realizada pelo conjunto que tem a finalidade de criar as condições necessárias para a construção desse conhecimento. (PARANÁ, 1987a, p. 5).

O documento Reorganização da Escola Pública de $1^{\circ}$ Grau: proposta preliminar de trabalho (PARANÁ, 1987b), editado durante esse período, também demonstra uma 


\title{
Revista HIISTESIDIR On-lime
}

preocupação com o currículo, trazendo em um de seus tópicos o subtítulo $2.7 \mathrm{~A}$ Reorganização do Currículo. Nele, enfatiza a importância dos programas de ensino para a escola, afirmando que devem ter um eixo comum, que não sejam isolados e pensem o pedagógico dentro das mesmas referências.

\begin{abstract}
Há um conjunto de fatores responsáveis pela melhoria da qualidade do ensino oferecido pelas escolas públicas. Entre eles, alguns devem indicar os eixos que deverão se constituir em pontos de partida para a reorganização do currículo e mais especificamente dos programas de ensino, de maneira que os diferentes componentes curriculares não caminhem isoladamente e de forma fragmentada nessa reorganização. É claro que cada campo de investigação científica tem sua especificidade e seus eixos próprios, mas todos eles devem estar articulados no currículo em torno de alguns eixos comuns que sejam coerentes e objetivem a proposta educacional global do sistema de ensino. (PARANÁ, 1987b, p. 12).
\end{abstract}

Analisando-se anteriormente o processo de elaboração do Currículo Básico para a Escola Pública do Estado do Paraná (1990), uma questão necessita ser respondida: Como foi o processo de efetivação desse documento editado em 1990, no último ano do governo de Álvaro Dias, Martins (1997, p. 110) alega que “[...] os Currículos de $1^{\circ}$ e $2^{\circ}$ não receberam suporte financeiro administrativo e político necessários a sua implementação." Os salários dos professores perderam poder de compra de forma considerável. Isso remete ao estudo de Baczinski (2007) quando se apoia em Zanella para entender que o fato de não ter havido um incentivo maior para que os professores se apropriassem de conhecimentos necessários para trabalhar com o Currículo Básico ${ }^{10}$ prejudicou o seu trabalho, sobre tudo daqueles que já lecionavam no Estado há alguns anos e não tiveram uma formação crítica, devido às proibições e limites impostos pela ditadura civil-militar vivenciada nas décadas anteriores.

A Pedagogia Histórico-Crítica,

[...] tal como foi formulada por Dermeval Saviani (1994 e 1997), é uma pedagogia marxista. [...] parte do pressuposto de que o dominado não se liberta se não vier a dominar o que o dominante domina, ou seja, é preciso que o dominado tenha acesso aos conhecimentos com base nas ciências e nas filosofias (conteúdos). Dominado aqui é a classe trabalhadora. Sem um conhecimento de classe social na perspectiva marxista, não é possível ser professor na perspectiva da filosofia da práxis. [...] Para trabalhar na pedagogia histórico-crítica, portanto, não basta apenas seguir os cinco passos tal como foram propostos por Saviani: prática social inicial, problematização, instrumentalização, catarse e prática social final. Faz-se necessário, [...] certo conhecimento dos pressupostos teórico-metodológicos do marxismo. Sem este conhecimento, corre-se o risco de se resvalar para o ecletismo ou de se fazer uma pedagogia dos que-fazeres. (BACZINSKI, 2007, p. 4).

Nesse processo, entendem-se as dificuldades do magistério paranaense à medida que foi obrigatória a implantação do Currículo Básico nas escolas do Paraná, sem que parte dos professores estivesse preparada para tal. Constatou-se que a participação de professores na elaboração do currículo, foi limitada a apenas um representante por NRE, o que não denota participação da grande maioria, que só teve a oportunidade de conhecer o material quando chegou à escola para utilização como norteador do trabalho docente. A participação dos 


\section{Revista HIISTESIDIR On-lime}

Artigo

doi: $10.20396 /$ rho.v18i2.8652356

professores nesse processo pode ser situada na participação concedida e, mesmo que Bordenave (1983, p. 29-30) considere que esse tipo de participação "[...] encerra em si mesma um potencial de crescimento da consciência critica, da capacidade de tomar decisões e de adquirir poder", esse despertar da consciência seria difícil para o professor na medida em que não entendia os pressupostos teórico-metodológicos da proposta, afirma Baczinski (2007).

O governo Requião, 1991-1994, divulgou seu Plano Global: educação básica - período 1992-1995 (PARANÁ, 1991), que tinha, segundo Baczinski (2007, p. 57), como uma das prioridades o "[...] aprofundamento do conhecimento científico ofertado no Currículo Básico do Ensino Fundamental e Médio.” Essa prioridade não se manteve, visto que o Currículo Básico foi praticamente ignorado durante seu governo, que deu maior ênfase às sugestões extracurriculares e a valorização do conhecimento científico não foi destacada quando se evidenciava como seria o trabalho com o currículo nas escolas.

Essa opção de esvaziamento do Currículo Básico pode ser percebida no Projeto Paraná: Construindo a Escola Cidadã (1992), que trazia um item para discutir o currículo, intitulado $O$ Currículo na Prática Escolar e se iniciava com a seguinte definição: "Com relação ao trabalho propriamente pedagógico, os experimentos inovadores estão relacionados mais com as atividades chamadas extracurriculares." (PARANÁ, 1992, p. 19). Ao acentuar que a inovação dar-se-ia fora das atividades curriculares, há um reforço quando se defende que as atividades extracurriculares são sensíveis ao novo, ganhando lugar de destaque nas atividades escolares. Os saberes fora do currículo ganharam visibilidade, enquanto o conhecimento curricular foi sendo abandonado. Enaltecia-se o fato de as escolas estarem tentando resolver o problema da evasão escolar ao integrarem escola-comunidade, sendo as "aulas práticas" apontadas como "saída" para manter o aluno na escola. E complementava:

2. Integrando as atividades chamadas de extracurriculares ao currículo. As diversas atividades, envolvendo Hortas, Jardins, Ervas Medicinais, Produtos Químicos, Criação de Bichos, Jornal, Fanfarra, Atividades Esportivas, Artísticas, além de exposições (interesse em socializar o conhecimento) etc., estão sendo consideradas por muitas escolas como atividade curricular, integrando-as às diversas disciplinas. [...].

3. O aluno como o sujeito do ato de conhecimento. Exemplo mais marcante desse princípio curricular está no sistema de monitoria: alunos interagindo no processo de aprendizagem de grupos de colegas. [...]. Há experimentos bem sucedidos de alunos atuando como palestrantes em assuntos como: Drogas, Aids, etc. [...]

4. Projetos na área de Iniciação ao Trabalho: Marcenaria, Artes Gráficas, Ajardinamentos e Hortas Domésticas, etc. [...]. (PARANÁ, 1992, p. 18-19).

Conforme Gonçalves et al. (2003), o governo Requião foi o primeiro a constituir empréstimos do BIRD: 200 milhões de dólares para ampliar o CB para três anos. Justamente naquele momento, houve mudança de discurso: o currículo que pedia o conhecimento científico, pautado nos conteúdos das disciplinas foi diferido. Não coincidentemente, nos anos 1990, foram implantadas no Brasil as políticas sugeridas pelas agências internacionais 
para os chamados países em emergência. Para Libâneo (2012), essas políticas, primeiro, desqualificavam as escolas que formavam tradicionalmente, que primavam pelo conteúdo não atraente aos alunos; segundo, sugeriam que estes deveriam ser preparados para a vida prática, com "ações socioeducativas", devendo a escola tomar outras formas, adaptar-se, aproximar-se das orientações dadas na Declaração Mundial sobre Educação para Todos, de 1990. Ao se incluir atividades como horta e jardins nos currículos escolares, colocam-se

[...] bem próximas da ideia de que o papel da escola é prover conhecimentos ligados à realidade imediata do aluno, utilizáveis na vida prática (como acreditam, também, algumas concepções mais simplistas da ligação do ensino à vida cotidiana). Em síntese, a aprendizagem transforma-se numa mera necessidade natural, numa visão instrumental desprovida de seu caráter cognitivo, desvinculada do acesso a formas superiores de pensamento. (LIBÂNEO, 2012, p. 18).

Ao analisar o documento Projeto Pedagógico - 1987-1990 (PARANÁ, 1987a), Parra (2008, p. 89), por sua vez, demonstra “[...] uma mudança de concepção de educação ao estabelecer uma crítica à centralidade do pensamento da pedagogia histórico-crítica nas políticas públicas, exemplificado no Currículo Básico", afirmando que o propósito de inovação da política educacional deste governo prioriza a inovação em detrimento do conhecimento sistematizado, defendido pelo $\mathrm{CB}$.

A este discurso, somam-se as palavras de Baczinski:

\begin{abstract}
Segundo Gonçalves, durante essa gestão, a concepção da Pedagogia HistóricoCrítica foi suprimida de tal forma que Olinda Evangelista e Maria Auxiliadora Schmidt, que ocuparam os cargos de Chefia e Assessoria Técnica do Departamento de Ensino de $1^{\circ}$ grau da SEED, de março até agosto de 1991, foram 'demitidas por incompatibilidade com a linha político-pedagógica que passou a orientar a gestão. A partir daí, nomes ligados à concepção histórico-crítica chegam a ser vetados para palestras, cursos, etc., no sistema de ensino'. (BACZINSKI, 2007, p. 65, grifo do autor).
\end{abstract}

Segundo Figueiredo (2001, p. 128), “[...] na gestão do governo Roberto Requião, as premissas do Banco Mundial começam a se definir com maior clareza [...] uma nova diretriz teórica com os pressupostos do neoliberalismo" passou a ser viabilizada no estado do Paraná.

\title{
1995 A 2002: EDUCAÇÃO NO MODELO NEOLIBERAL
}

Jaime Lerner, que iniciou o seu primeiro mandato pelo PDT e filiou-se ao PFL ainda no decorrer da sua primeira gestão, de 1995 a 1999, trouxe como lema à SEED o slogan excelência na educação. O documento norteador da educação, apresentado por sua gestão, foi o Plano de Ação 1995-1998 - SEED (PARANÁ, 1995), que focava a gestão compartilhada, defendia a união entre estado e comunidade para o bem da educação, sendo que os diretores das unidades escolares deveriam aderir, compartilhando com a comunidade ou clientela, como eram denominados alunos e seus responsáveis legais, ficando livres para 
buscar parcerias com o setor privado quando as verbas necessárias para o funcionamento da escola não chegavam.

O estudo de Tavares esclarece os caminhos que o "gestor escolar" deveria seguir:

O primeiro é organizar o trabalho da Associação de Pais e Mestres (APM) para que, através de festas ou campanhas, haja arrecadação de recursos entre os pais e moradores do bairro/município onde a escola está localizada. A APM ainda pode cobrar taxas dos seus associados.

O segundo é fazer parcerias com empresas locais de modo a disponibilizar o prédio escolar para exposição de outdoor e para propagandas em muros, além de disponibilizar salas para oferecimento de cursos de inglês ou computação cujas taxas podem reverter em parte para a escola.

O terceiro caminho é o do relacionamento político com os empresários locais, prefeito, vereadores e outras lideranças que podem disponibilizar recursos de verbas de representação e outras. (TAVARES, 2004, p. 3).

Sobre o Plano de Ação 1995-1998 - SEED (PARANÁ, 1995), Parra faz a seguinte análise:

O Plano de Ação apresenta três focos de atuação. O primeiro diz respeito à permanência do aluno na escola com êxito, utilizando, como instrumentos para tal, a correção de fluxo escolar, a revisão do currículo básico, suporte ao ciclo básico de educação, e avaliação do rendimento escolar do aluno. O segundo se refere à atuação dos professores na escola e o desenvolvimento de suas competências através de capacitação presencial e à distância, produção de materiais de suporte ao currículo, incentivo financeiro pela participação em projetos educacionais e pelo exercício da gestão compartilhada. O terceiro propõe a participação efetiva da comunidade utilizando [...], a efetivação de parcerias com o setor produtivo da sociedade, a revisão do processo de integração Estado X Município, a revisão da forma de participação da comunidade na escola e a proposta de monitoramento da comunidade sobre o setor educacional. (PARRA, 2008, p. 106-107).

Nos três focos destacados do Plano de Ação, é possível verificar que a gestão cumpriu prontamente suas metas:

a) a diminuição do tempo do aluno na escola, o Projeto Correção de Fluxo ${ }^{11}$ que, de acordo com Marochi (2000, p. 136), “[...] teve um alcance sem precedentes no enfrentamento do fracasso escolar da $5^{\mathrm{a}}$ à $8^{\mathrm{a}}$ série do ensino fundamental no Paraná";

b) a criação da Universidade do Professor, que, conforme Gentili (1998, p. 331), tinha como objetivo primeiro "[...] replicar no campo pedagógico experiências formativas ou organizacionais próprias do campo empresarial”, entoado o discurso de que o professor era o agente responsável pela melhoria da educação. Estes se viam, “[...] muitas vezes, constrangidos a tomarem para si a responsabilidade pelo êxito ou insucesso dos programas" (OLIVEIRA, 2004, p. 1131-1132) por onde passaram mais de "[...] 195 mil participantes de eventos de capacitação.” (SAMPAIO, 2010, p. 11). 
c) a participação da comunidade na escola, mais especificamente, “[...] parceria com o setor produtivo da sociedade", com "[...] a criação de empresas de direito privado que passaram a administrar parcelas das atividades da área educacional da Secretaria de Estado da Educação, convivendo na estrutura do aparelho de Estado." ${ }^{\prime 2}$ (TAVARES, 2004, p. 67). Essa meta vem atender claramente às políticas neoliberais de Estado mínimo e privatização, que "[...] atribui ao Estado os males sociais e econômicos de nossa sociedade atual e à livre iniciativa todas as virtudes que podem conduzir à regeneração e recuperação da democracia, da economia e da sociedade." (SILVA, 1995, p. 11).

Em seu segundo mandato (1999/2003), houve a continuidade da política de governo. Nos oito anos de gestão, os programas implementados pela SEED foram: o Projeto Qualidade do Ensino Básico do Paraná, política do governo anterior, mas encampado vigorosamente; o Programa Expansão, Melhoria e Inovação do Ensino Médio do Paraná; o Programa Correção de Fluxo e a continuidade da municipalização dos anos iniciais do ensino fundamental. Todos esses projetos geraram apoio financeiro do BIRD, sendo que, deste último, saíram técnicos para formar o quadro administrativo do governo Lerner. O principal exemplo da ajuda de "recursos humanos" foi da própria secretária da educação Alcyone Saliba ${ }^{13}$ que, antes de assumir o cargo na administração paranaense, era funcionária do Banco Mundial. (GONÇALVES et al., 2003).

Com relação ao currículo, nesse período, o processo de descentralização foi uma política efetivada, e uma das suas características foi responsabilizar cada escola sobre o que ensinar. Tavares (2004, p. 46) chama a atenção para a pesquisa de Maria Dativa de Salles Gonçalves, realizada em1994, na qual afirma que, pós 1990, a autonomia da escola estava diretamente ligada à ideia de "[...] renovação pedagógica, levando à perda da perspectiva da escola unitária que havia orientado, entre as políticas anteriores, a da elaboração do 'Currículo Básico' para as escolas de ensino fundamental."

As escolas estavam orientadas no sentido de que a autonomia se estendia em relação a projetarem currículos adequados aos seus alunos, uma vez que, segundo o discurso da política educacional neoliberal vigente, que também usava a autonomia como estratégia política para transferir a responsabilidade do sistema educacional para a sociedade civil, somente os "gestores" conheciam a realidade da comunidade e poderiam sugerir uma grade curricular apropriada. Essa autonomia era balizada pelas imposições das Instituições Multilaterais de Financiamento: o BIRD e o BID. As instituições capitalistas visam ao lucro, seja advindo dos altos juros cobrados sobre os empréstimos, seja quando garantem um tipo de formação que dê base para a continuidade do mercado produtivo, impingindo características necessárias para a mão de obra. A flexibilidade, por exemplo, é um dos atributos que o trabalhador deve ter; existem ganhos à medida que esse trabalhador flexível transforma-se em um consumidor flexível, garantindo a mundialização do capitalismo. 
Como a produção flexível sem 'consumidores flexíveis', isto é, sem sujeitos receptivos à efemeridade das mercadorias, não resultaria em venda, os sujeitos são, desde a tenra infância, cuidadosamente educados para gostarem das novidades, identificarem-se com o último lançamento, aderirem às modas efêmeras. (GALUCH; SFORNI, 2011, p. 57).

O documento Proposta Pedagógica e Autonomia da Escola: Novos Paradigmas Curriculares e Alternativas para a Organização Pedagógica na Educação Básica Brasileira (PARANÁ, 2000), assinado por Guiomar Nano de Mello, Maura Chezzi Dallan e Vera Grellet, balizou as políticas da SEED no segundo mandato de Jaime Lerner, definindo que o currículo deveria ser direcionado pela Lei de Diretrizes e Bases (LDB), privilegiando as competências estabelecidas como "[...] necessárias à inserção no mundo da prática social e do trabalho." (PARRA, 2008, p. 171). Prevalece, assim, um currículo adequado ao mercado, "[...] tendo por finalidade administrar a pobreza e promover a segurança, a partir da construção da cidadania e preparação para o trabalho.” (FIGUEIREDO, 2001, p. 153).

Piton (2004) analisa algumas mudanças impostas pela legislação nacional, prontamente seguidas no Paraná, e que incidem diretamente sobre o currículo. Entre elas, constam redução de carga horária de algumas disciplinas como Língua Portuguesa, Matemática, Ciências, História e Geografia; a ampliação do quadro curricular e a criação de disciplinas ${ }^{14}$ que atendiam ao desenvolvimento de competências e habilidades e ao conceito de cidadania. Todas as disciplinas passaram a dar um enfoque na cidadania, mais precisamente à "cidadania competitiva"; no ensino fundamental e no ensino médio, inclusive, foi criada a disciplina Cidadania e Direito, cujo programa era constituído de "temas ligados ao empreendedorismo". Piton, em sua tese, narra uma passagem esclarecedora acerca desta disciplina:

\begin{abstract}
A questão do empreendedorismo foi constante. O Colégio Estadual de Cascavel, por exemplo, durante a distribuição de aula, a disciplina entrou em disputa, pois todos os professores se julgavam aptos a ministrar a disciplina. Mas o diretor disse que não poderia ser qualquer um, pois, já havia comprado os materiais necessários para desenvolvimento da disciplina no ano. Fomos então verificar que materiais e os materiais eram linha, agulha, tinta, para que ele aprendesse a bordar, a pintar, para que os alunos se desenvolvessem como um empreendedor nesta área. (PITON, 2004, p. 118).
\end{abstract}

As orientações propostas pela SEED naquele momento formalizaram o esvaziamento do currículo. As disciplinas curriculares que garantiam determinados conhecimentos, por propiciarem a apropriação de conceitos sistematizados, foram desconsideradas e, em seu lugar, "saberes" foram elevados à categoria de conhecimentos. "Os conteúdos formais das diferentes disciplinas escolares passam a dividir espaço com outros conteúdos, temas sociais ou metodologias [...]”. (GALUCH; SFORNI, 2011, p. 61). Quais são as implicações quando se sugeria um currículo baseado em saberes cotidianos?

Quando o currículo escolar sugerido desconsidera os conhecimentos universais, que são detidos pelas áreas específicas e carregam consigo conceitos que foram apropriados pelo 
homem e, por isso mesmo, possibilitaram a ele o desenvolvimento humano, tanto pela hominização quanto pela humanização, concede-se aos alunos uma formação alijada, que não os ajuda a construir generalizações que o conhecimento sistematizado oportuniza. Os currículos baseados em saberes cotidianos, tidos como democráticos, por respeitarem e valorizarem a cultura de cada comunidade, levam os alunos a uma circularidade, já que não propõem o conhecimento teórico dessa realidade, atêm-se aos seus aspectos visíveis.

No caso da disciplina de História, não basta conhecer a comunidade hoje, mas compreender como ela chegou até aqui, o porquê de os homens que a compõem ocuparem esse lugar e não outro dentro de uma cadeia produtiva. Esse conhecimento somente poderá ser adquirido por meio da história-ciência, que domina os conceitos históricos que ajudam na compreensão, porque, ao contrário, esse conhecimento não possibilita entender a totalidade, entender que o local é explicado pelo total, que sua comunidade é fruto de um mundo globalizado, em que, para conhecê-la, é preciso conhecer o mundo, munido de conceitos sistematizados, estabelecendo uma relação mediada com a experiência pessoal, o particular revelado no universal e o universal expressado no particular.

Nesse período, o Currículo Básico para a Escola Pública do Estado do Paraná ${ }^{15}$ foi sucessivamente suprimido, seja pela ampliação da grade curricular com disciplinas extras, seja pela própria descaracterização dos conteúdos das disciplinas que passaram a ter um enfoque na cidadania, no entendimento do cotidiano, seguindo orientações de documentos como o Relatório Delors, a fim de formar um aluno mais adaptável ao mercado, em condições de disputar uma vaga de trabalho e ocupar seu lugar de consumidor ajustado, favorecendo a permanência das condições socioeconômicas capitalistas. Outro ponto que essa descaracterização das disciplinas pressupõe é a retração do ensino de conhecimentos historicamente produzidos pela sociedade, que favorecem o processo de humanização e que, portanto, devem ser socializados na escola, para continuar promovendo o desenvolvimento. Lembrando que o modelo de cidadania enfocado pelos conteúdos escolares fortalece a cidadania enquanto obrigações políticas dos indivíduos, promovendo a continuidade e não a mudança social.

\section{CONSIDERAÇÕES FINAIS}

A eleição de um candidato de oposição aos militares como governador do estado do Paraná em 1982 não garantiu uma política educacional voltada para atender aquela parte da população paranaense que necessitava de uma escola mais democrática, na qual pudessem se desenvolver nos alunos a capacidade de entendimento da sociedade e sua preparação para atuar de forma efetiva nas mudanças sociais, econômicas e culturais que seriam indispensáveis naquele momento, mesmo propondo uma metodologia da teoria Históricocritica, as orientações aos professores ofereceram uma formação mais "espiritualmente humanizadora". A democratização da sociedade se resumiu em aumentar o número de alunos 
matriculados nas instituições escolares se aproximando das indicações dos órgãos internacionais que apontavam sobre a necessidade de colocar crianças e jovens no sistema educacional, afirmando que a educação resolveria os problemas econômicos por que passavam os países.

As políticas públicas para a educação efetivadas por outros governadores que se seguiram vão se aproximando cada vez da proposta neoliberal para os países pobres se desenvolvessem, seja na intencionalidade que formar os diretores de escolas como gestores empresariais, que deveriam administrar suas escolas como gestores de empresas privadas, modelo implantado na Secretaria de Educação e estendido aos demais órgãos do sistema educacional no Paraná a partir de 1987. Outro ponto atentado foi a descentralização de poder, que levou a abertura das escolas para a comunidade, afirmando que a democratização das escolas levaria a uma superação dos problemas educacionais, a comunidade foi chamada a participar da vida escolar, seja na parte pedagógica, seja na manutenção das escolas, retirando do governo determinadas responsabilidades.

Se entre 1982 a 1994 pudemos perceber determinadas práticas neoliberais sendo adotadas por governos que se colocavam contra tal modelo, a partir de 1995 até 2002 pudemos acompanhar sua adoção integral pelas políticas públicas dirigidas à educação paranaense, seja na formação continuada de professores, na qual empresas privadas foram contratadas para dar os cursos aos profissionais da educação, tratando-os como funcionários de empresas, que deviam primar pela qualidade de ensino, serem flexíveis e resolver os problemas das suas escolas sem recorrer aos seus superiores, o bom funcionário era aquele que solucionava problemas de forma individual. Os currículos escolares foram esvaziados de conteúdos teóricos atendo-se a uma formação baseada no cotidiano dos alunos, mas sem ensiná-los a compreender a sociedade em que estão inseridos como resultado de um processo histórico, construído pelo homem e portanto, passível de mudanças por meio da ação deste próprio homem.

Esse modelo de política educacional foi nefasto para a educação paranaense, como o professor foi responsabilizado individualmente pelos problemas da educação, deveria ser também individual a luta para melhorá-la, esse discurso acabou por enfraquecer a ação coletiva dos professores. As escolas ficaram abandonadas com o processo de descentralização a qual foram expostas, favorecendo a privatização do ensino e o fortalecimento das instituições educacionais privadas, que apontavam a desorganização das escolas públicas em suas propagandas para aumentar sua clientela.

Rever este processo nos auxilia na compreensão de que políticas públicas favorecendo a diminuição da responsabilidade do Estado frente à educação são danosas para aquela parte da população que mais depende do ensino público.

\section{REFERÊNCIAS}


BACZINSKI, A. V. de. M. A implantação oficial da pedagogia histórico-critica no estado Paraná (1983-1994): legitimação, resistência e contradição. 2007. 154 f. Dissertação (Mestrado em Educação) - Universidade Estadual de Campinas, Campinas, SP, 2007.

BORDENAVE, J. D. O que é participação. São Paulo: Brasiliense, 1983.

CUNHA, L. A. Educação, estado e democracia no Brasil. São Paulo: Cortez; Niterói, RJ: Editora Federal Fluminense; Brasília, DF: FLACSO do Brasil, 1991.

EVANGELISTA, O.; SCHMIDT, M. A. Relação estado/município no Paraná: construção ou desconstrução da escola pública de qualidade? In: VELOSO, J. et al. (Org.). Estado e educação. Campinas, SP: Papirus, 1992. p. 279-297. (Coletânea CBE).

FIGUEIREDO, I. M. Z. Políticas educacionais do estado do Paraná nas décadas de 80 e 90: da prioridade à "centralidade da educação básica". 2001. 179 f. Dissertação (Mestrado em Educação) - Universidade Estadual de Campinas, Campinas, SP, 2001.

FIORI, J. L. Os moedeiros falsos. 5. ed. Petrópolis, RJ: Vozes, 1998.

GALUCH, M. T. B.; SFORNI, M. S. de. F. Interfaces entre políticas educacionais, prática pedagógica e formação humana. Práxis Educativa, Ponta Grossa, v. 6, n. 1, p. 55-66, jan./jun. 2011. Disponível em: <http://www.periodicos.uepg.br>. Acesso em: 01 jan. 2013.

GENTILI, P. A complexidade do óbvio: A privatização e seus significados no campo educacional. In: SILVA, L. H. (Org.). A escola cidadã no contexto da globalizaçãa. Petrópolis, RJ: Vozes, 1998. p. 320-339.

GONÇALVES, M. D. de. S. et al. A presença do Banco Mundial e do Banco Interamericano no financiamento do ensino fundamental e médio na Rede Estadual de Ensino do Paraná. Educar em Revista, v. 21, n. 2. Especial, p. 71-99, 2003.

LIBÂNEO, J. C. O dualismo perverso da escola pública brasileira: escola do conhecimento para os ricos, escola do acolhimento social para os pobres. Educação e Pesquisa, v. 38, n. 1, p. 13-28, 2012.

LIMA, A. B.; VIRIATO, E. O. As políticas de descentralização, participação e autonomia: desestatizando a educação pública. In: REUNIÃO ANUAL DA ANPED, 23., Caxambu, MG, 2005. Anais eletrônicos... Caxambu, MG, 2005. p. 1-15. Disponível em: <http://anped.org.br/reuniões/28/gt06.htm>. Acesso em: 25 out 2014.

MAINARDES. J. Ciclo básico de alfabetização: da intenção à realidade. (Avaliação do CBA no Município de Ponta Grossa - PR). 1995. 239 f. Dissertação (Mestrado em Educação) - Universidade Estadual de Campinas, Campinas, SP, 1995.

MÂNFIO, A. J. A proposta pedagógica como instrumento de qualidade e de gestão da escola: conteúdo, processo de elaboração, acompanhamento e avaliação: a participação do magistério. Curitiba: SEED, 1993. 
MAROCHI, Z. M. L. Projeto de correção de fluxo: um marco referencial na educação do Paraná. Em Aberto, Brasília, DF, v. 17, n. 71, p. 134-138, jan. 2000.

MARTINS, R. B. Escola cidadã do Paraná: análise de seus avanços e retrocessos. 1997. $271 \mathrm{f}$. Tese (Doutorado em Educação) - Universidade Estadual de Campinas, Campinas, SP, 1997.

NORONHA, O. M. Políticas neoliberais, conhecimento e educação. Campinas, SP: Alínea, 2002.

OLIVEIRA, D. A. A reestruturação do trabalho docente: precarização e flexibilização. Educação e Sociedade, Campinas, SP, v. 25, n. 89, p. 1127-1144, set./dez. 2004. Disponível em: 〈http://www.cedes.unicamp.br〉. Acesso em: 05 abr. 2012.

PARANÁ (Estado). Secretaria de Estado da Educação. Políticas SEED - PR; fundamentos e explicitação. 3. ed. Curitiba: SEED, 1984.

PARANÁ (Estado). Secretaria de Estado da Educação. Projeto Pedagógico: 1987 - 1990. Curitiba: SEED, 1987a.

PARANÁ (Estado). Secretaria de Estado da Educação. Reorganização da escola pública de $\mathbf{1}^{\circ}$ grau: proposta preliminar de trabalho. Curitiba: SEED, 1987b.

PARANÁ (Estado). Secretaria de Estado da Educação. Plano global: educação básica período 1992-1995. Curitiba: SEED, 1991.

PARANÁ (Estado). Secretaria de Estado da Educação. Superintendência de Educação. Paraná: Construindo a Escola Cidadã. Curitiba: SEED, 1992.

PARANÁ (Estado). Secretaria de Estado da Educação. Avaliação escolar: um Compromisso Ético. Curitiba: SEED, 1993.

PARANÁ (Estado). Secretaria de Estado da Educação. Inovando nas escolas do Paraná. Brasília, DF: Instituto Nacional de Estudos e Pesquisas Educacionais, 1994.

PARANÁ (Estado). Secretaria de Estado da Educação. Plano de Ação 1995-1998. Curitiba: SEED, 1995.

PARANÁ (Estado). Secretaria de Estado da Educação. Proposta pedagógica e autonomia da escola: Novos paradigmas curriculares e alternativas de organização pedagógica na educação básica brasileira. Curitiba: SEED, 2000.

PARANÁ (Estado). Secretaria de Estado da Educação. Superintendência da Educação.

Transferências de recursos para empresas parceiras 1999-2002. Curitiba: SEED, 2003.

PARTIDO DO MOVIMENTO DEMOCRÁTICO BRASILEIRO - PMDB. Uma educação para a modernidade: propostas de ações governamentais para o ensino do Paraná (Roberto Requião). Curitiba, 1990. 
PARRA, S. O processo de conversão da idéia de projeto político pedagógico em política educacional pública no estado do Paraná (1983-2002). 2008. 173 f. Dissertação (Mestrado em Educação) - Universidade Federal do Paraná, Curitiba, 2008.

PITON, I. M. Políticas educacionais e movimento sindical docente: reformas educativas e conflitos docentes na educação básica paranaense. 2004. 293 f. Tese (Doutorado em Educação) - Universidade Estadual de Campinas, Campinas, SP, 2004.

SAMPAIO, C. M. A. Nova atmosfera, novo modelo e o velho princípio do mercado: o neoliberalismo e as políticas públicas de educação no Paraná de 1995 a 2002. In: SEMINÁRIO SOCIOLOGIA \& POLÍTICA. 2., 2010, Curitiba, Anais... Curitiba: Universidade Federal do Paraná, 2010. p. 1-25.

SHIROMA, E. O.; EVANGEliStA, O.; MORAES, M. C. M. de. Política educacional. 4. ed. Rio de Janeiro: Lamparina, 2011.

SILVA, C. G.; AZZI, D.; BOCK, R. Banco Mundial em foco: um ensaio sobre a sua atuação na educação brasileira e na da América Latina. São Paulo: Ação Educativa, 2007. Disponível em: <http://www.bdae.org.br/dspace/bitstream/123456789/2348/1/banco _mundial_em_foco.pdf.>. Acesso em: 10 out. 2013.

SILVA, T. T. da. A "nova" direita e as transformações na pedagogia da politica e na política da pedagogia. In: GENTILI, P. A. A.; SILVA, T. T. da. (Org.). Neoliberalismo, qualidade total e educação. 2. ed. São Paulo: Vozes, 1995. p. 9-29.

TAVARES, T. M. Gestão pública do sistema de ensino no Paraná (1995-2002). 2004. 161 f. Tese (Doutorado em Educação) - Pontifícia Universidade Católica, São Paulo, 2004.

WOOD, E. M. Democracia contra capitalismo: a renovação do materialismo histórico. Trad. Paulo Cezar Castanheira. São Paulo: Boitempo, 2011.

\section{Notas}

${ }^{1} \mathrm{O}$ presente trabalho é parte da pesquisa realizada para a tese intitulada A Elaboração das Diretrizes Curriculares da Educação Básica do Estado do Paraná - História: uma análise sobre a participação dos professores, defendida junto ao Programa de Pós-Graduação em Educação da Universidade Estadual de Maringá em 2014. Tendo como orientadora a docente Maria Terezinha Bellanda Galuch.

${ }^{2}$ Professora Ajunta do Colegiado de História da Universidade Estadual do Norte do Paraná, doutora pela Programa de Pós-Graduação em Educação da Universidade Estadual de Maringá.

${ }^{3}$ Professora do Departamento de Teoria e Prática da Educação e do Programa de Pós-Graduação em Educação da Universidade Estadual do Norte do Paraná.

${ }^{4}$ O Programa do Partido do Movimento Democrático Brasileiro, no período, intitulava-se "Democracia e justiça social: diretrizes de um programa de governo".

${ }^{5}$ Cf. Luiz Antonio Cunha (1991, p. 23), as propostas do PMDB para a eleição de 1982 defendiam a tarefa da escola como educação libertária.

${ }^{6}$ Gilda Poli Rocha Loures coordenou a Secretaria de Educação do Estado do Paraná em duas ocasiões: 16/03/1987 a 09/01/1989 e 11/01/1989 a 5/03/1991. 


\section{Revista HIISTETIDBR On-line}

${ }^{7}$ Em nota, Rosilda Baron Martins (1997) esclarece que tal incoerência foi responsável pela demissão do então chefe do Departamento de Ensino do $1^{\circ}$ Grau. O diretor do Departamento do Ensino de $1^{\circ}$ Grau (ex-secretário da Educação de Lages-SC) tinha ideias bastante originais a respeito do currículo do ensino de $1^{\circ}$ grau. Sua ótica de "compromisso popular" levou-o a imaginar a criação de "[...] reservas protetoras da infância para crianças de 0 a 6 anos, onde, através de brincadeiras, receberiam noções de higiene corporal, alimentação e estimulação sensório-motora, artes plásticas, teatro. Aos 9 anos, iniciaria o aprendizado das letras nos laboratórios de ler e escrever. Os alunos de 12 a 14 anos frequentariam os 'barracões-oficinas', estabelecendo uma ligação entre conhecimento e o trabalho prático. Essas ideias não chegaram a sair do papel. Foram rejeitadas pelas direções das escolas, movidas por um senso pedagógico, resistindo às tentativas do diretor do DEPG de convertê-las na nova educação que pretendia implantar.” (MARTINS, 1997, p. 106).

${ }^{8}$ A Associação dos Professores do Paraná foi criada em abril de 1947 por professores do Instituto de Educação do Paraná. Em 1989, passa a ser Sindicato dos Professores das Redes Pública Estadual e Municipais do Paraná, adotando a sigla APP - Sindicato. Hoje é o sindicato dos professores, pedagogos e funcionários das escolas paranaenses.

${ }^{9}$ Criado em 1987, pelo Departamento de Ensino do $1^{\circ}$ Grau, o Ciclo Básico de Alfabetização - CBA. O Decreto n. 2545/1988 do Governo do Estado do Paraná foi instituído o CBA nas escolas de $1^{\text {o }}$ grau da Rede Estadual de Ensino, garantindo ao aluno o prolongamento do tempo de alfabetização inicial de 1(um) para 2 (dois) anos. ${ }^{10}$ O Currículo Básico Para a Escola Pública do Estado do Paraná foi denominado de Currículo Básico por professores das escolas paranaense.

${ }^{11}$ Segundo Marochi (2000, p. 134-138) o Projeto Correção de Fluxo foi implantado no estado do Paraná, como o primeiro a promover a aceleração no país, no qual os alunos cursavam até três séries em um ano, com a finalidade de atender aos alunos multirrepetentes, atendidos em salas específicas com material próprio. Zélia Maria Lopes Marochi foi coordenadora do projeto de 1997 a 1999. As Instituições de Ensino Superior estaduais também tiveram uma participação no Projeto Correção de Fluxo: universidades paranaenses foram envolvidas durante a implementação do Projeto, de modo a contribuir para o seu monitoramento e orientação na superação de eventuais dificuldades: "[...] houve uma parceria com as universidades, cujos professores tiveram a incumbência de visitar os Núcleos Regionais de Educação e as escolas, com o objetivo de acompanhá-los e dar apoio teórico-metodológico, para resolver os problemas." (LÜCK; PARENTE, 2002, p. 24). Na Universidade Estadual de Maringá, o referido projeto foi assessorado pela professora Marta Sueli de Faria Sforni.

${ }^{12}$ Cf. Tavares (2004, p. 68), estas empresas podem ser consideradas a face mais explícita da privatização do setor educacional. Os dados apresentados pela atual Superintendente de Educação da SEED/PR, em 26 de setembro de 2003, demonstram o volume de recursos repassado para essas empresas no período estudado. Transferência de recursos (em reais) para as empresas parceiras - 1999-2002.

\begin{tabular}{|c|c|c|c|}
\hline \multirow{2}{*}{ ANO } & \multicolumn{3}{|c|}{ Transferência do Estado } \\
\cline { 2 - 4 } & PARANÁ EDUCAÇÃO & PARANTEC & UNIVERSIDADE DO PROFESSOR \\
\hline 1999 & $35.368 .674,92$ & $1.904 .200,65$ & $997.318,03$ \\
\hline 2000 & $64.247 .075,78$ & $3.945 .681,93$ & $1.977 .643,51$ \\
\hline 2001 & $82.263 .127,19$ & $3.981 .787,39$ & $10.714 .000,00$ \\
\hline 2002 & $135.922 .636,79$ & $3.193 .018,62$ & $7.486 .893,00$ \\
\hline
\end{tabular}

Fonte: Paraná. Superintendência de Educação (2003).

13 Alcyone Vasconcelos Rebouças Saliba coordenou a Secretaria de Estado da Educação de 01/01/1999 a 02/09/2002.

${ }^{14} \mathrm{O}$ estado do Paraná chegou a ter, durante o segundo mandato de Jaime Lerner, cerca de 1700 disciplinas curriculares; as escolas tinham autonomia para inserir, na sua grade curricular, a disciplina que considerassem necessária à realidade do seu bairro.

15 O Currículo Básico continha propostas para as disciplinas de Língua Portuguesa, Matemática, História, Geografia, Ciências, Educação Artística, Educação Física, Língua Estrangeira Moderna, Organização Social e Política do Brasil, Pré-escola e Alfabetização.

Submetido em: 29/04/2018

Aprovado em: 16/05/2018

Publicado em: 22/06/2018 